\title{
PENGEMBANGAN MEDIA PEMBELAJARAN INTERAKTIF MATA PELAJARAN FISIKA PADA SISWA SMK
}

\author{
Lavanter Johansen Simamora ${ }^{1}$ dan Binsar Panjaitan ${ }^{2}$ \\ SMK Negeri 1 Balige ${ }^{1}$ dan Universitas Negeri Medan ${ }^{2}$ \\ lavan1477@yahoo.co.id ${ }^{l}$
}

\begin{abstract}
Abstrak: Penelitian ini bertujuan untuk mengetahui Pengembangan Media Pembelajaran Interaktif Mata Pelajaran Fisika. Pengembangan media pembelajaran interaktif mata pelajaran fisika ini diperoleh melalui observasi dari guru dan siswa di SMK Negeri 1 Balige, menyatakan media interaktif dibutuhkan dalam pembelajaran. Penelitian dan pengembangan menurut Borg \& Gall (1981). Prosedur penelitian ini terdiri dari: (1) tahap pertama melakukan penelitian pendahuluan; (2) tahap kedua pembuatan desain software; (3) tahap ketiga pengumpulan bahan; (4) tahap keempat membuat dan memproduksi media pembelajaran interaktif; dan (5) tahap kelima yaitu review atau uji lapangan dalam rangka evaluasi formatif dan revisi produk. Hasil penelitian dan pengembangan menunjukkan bahwa: (1) produk media interaktif mata pelajaran Fisika ini dikemas dalam bentuk Compact Disk, (2) validasi para ahli secara umum menyatakan kualitas produk media interaktif ini termasuk dalam kriteria 91,34\%, pengujian hipotesis produk media interaktif ini dinyatakan efektif digunakan untuk pembelajaran momentum \& impuls dimana terdapat perbedaan yang signifikan antara hasil belajar siswa kelas kontrol dan kelas eksperimen. Hasil pengolahan data dengan menggunakan uji t satu pihak diperoleh harga $t_{\text {hitung }}$ seharga 1,939 lebih besar dari $t_{\text {tabel }}$ seharga 1,676 maka dapat dinyatakan bahwa pengembangan media interaktif pembelajaran momentum \& impuls telah teruji efektif.
\end{abstract}

Kata Kunci: fisika, momentum \& impuls, media interaktif

Abstract: This study aims to determine the development of Interactive Learning Media Subject Physics. Developing interactive learning media physics obtained through observation of teachers and students in SMK Negeri 1 Balige, said interactive media needed in learning. Research and development according to Borg and Gall (1981). The procedure of this study consists of: (1) the first stage of a preliminary investigation; (2) The second phase of design creation software; (3) The third stage of collecting materials; (4) The fourth stage of creating and producing interactive learning media; and (5) the fifth stage is a review or a field test in the framework of the formative evaluation and revision of the product. Results of research and development show that: (1) interactive media products subjects of Physics is packaged in the form of Compact Disks, (2) validation of the experts generally stated the quality of interactive media products included in the criteria of $91.34 \%$, hypothesis testing interactive media products This is expressed effectively used for learning momentum and impulse where there is a significant difference between the results of student learning and classroom control classroom experiments. The results of data processing by using the t test of the parties thitung price obtained for 1,939 greater than 1,676 ttabel for it can be stated that the development of interactive media learning momentum and impulse has been proven effective.

Keywords: physics, momentum and impulse, interactive media

\section{PENDAHULUAN}

Jenjang pendidikan sekolah terdiri dari pendidikan dasar, pendidikan menengah, dan pendidikan tinggi. Pendidikan menengah diselenggarakan untuk melanjutkan atau memperluas pendidikan dasar serta menyiapkan peserta didik menjadi anggota masyarakat yang memiliki kemampuan mengadakan hubungan timbal balik dengan lingkungan sosial, budaya, dan alam sekitar serta dapat mengembangkan kemampuannya lebih lanjut dalam dunia kerja atau pendidikan tinggi.

Pendidikan menengah terdiri dari: (a) pendidikan umum, (b) pendidikan kejuruan, (c) pendidikan luar biasa, (d) pendidikan kedinasan dan (e) pendidikan agama. Salah satu bentuk pendidikan menengah adalah Sekolah Menengah Kejuruan (SMK).

Menurut Undang-Undang Sistem Pendidikan Nasional Tahun 2003 Pasal 15 
menyebutkan bahwa "Pendidikan kejuruan merupakan pendidikan menengah yang mempersiapkan peserta didik terutama untuk bekerja dalam bidang tertentu". Sebagai salah satu sekolah yang menghasilkan lulusan siap kerja dituntut untuk memiliki keterampilan untuk memasuki lapangan kerja, yang sesuai dengan kebutuhan masyarakat.

Sekolah Menengah Kejuruan (SMK) merupakan sekolah kejuruan yang terdiri dari kelompok Teknologi dan Industri, masingmasing program studi di SMK memiliki tujuan khusus yang berbeda satu dengan yang lainnya.

SMK merupakan salah satu lembaga pendidikan yang mengemban amanah untuk menghasilkan tamatan yang memiliki kompetensi tenaga kerja tingkat menengah. Kompetensi dimaksud mencakup seperangkat pengetahuan, keterampilan, dan perilaku bagi siswa untuk melaksanakan tugas tertentu. Acuan yang digunakan untuk memenuhi komptetensi siswa ialah kompetensi yang dibutuhkan oleh dunia kerja baik Standar Kompetensi Kerja Nasional Indonesia (SKKNI) atau standar kompetensi suatu lembaga internasional yang kredibelitasnya telah diakui secara global. Salah satu indikasi keberhasilan sekolah dalam mewujudkan siswa yang berkualitas adalah ditunjukkan dengan hasil belajar yang tinggi.

Mata pelajaran Fisika merupakan salah satu mata pelajaran yang wajib dipelajari oleh siswa Sekolah Menengah Kejuruan (SMK). Untuk jenjang SMK pelajaran Fisika sangat diperlukan dikarenakan sangat berkaitan dengan bidang kompetensi kejuruan masing-masing, selain itu lingkup materi mata pelajaran Fisika SMK dibatasi konsep-konsep dasar, juga perlu dilakukan pengembangan dan pendalaman materi tertentu yang dibutuhkan di lingkup program studi keahlian sehingga perlu dialokasikan porsi topik/materi Fisika dalam mata pelajaran dasar kejuruan di tiap program studi keahlian (Contoh : di program studi Teknik Bangunan, mekanika, salah satu topik/materi Fisika dibutuhkan secara lebih mendalam oleh program studi teknik bangunan, dialokasikan dalam mata pelajaran mekanika teknik). Sehingga setiap siswa dituntut untuk mampu mempersiapkan diri menghadapi perubahan keadaan di dalam dunia industri dan dunia usaha yang selalu berkembang baik melalui latihan, bertindak atas dasar pemikiran secara logis, rasional, kritis, cermat, jujur, efisien, dan juga membina kerjasama yang baik antar sesama siswa.
Dari hasil observasi awal, ditemukan beberapa fenomena pendekatan pembelajaran yang dilakukan guru dalam pengajaran Fisika, antara lain: (1) pendekatan pembelajaran masih terlalu didominasi guru (teacher centered), seperti guru lebih banyak menggunakan pendekatan ceramah tanpa diiringi pendekatan lain, (2) penggunaan pendekatan kurang tepat dengan materi pembelajaran, seperti tidak dihubungkan dengan bentuk nyata, (3) pembelajaran yang dilakukan tidak menggunakan media yang menantang siswa dalam pembelajaran, akibatnya guru lebih banyak menempatkan siswa sebagai objek dan bukan sebagai subjek didik.

Fenomena permasalahan di atas mengindikasikan bahwa metode pembelajaran yang digunakan guru dalam pengajaran Fisika di SMKN1 Balige masih bersifat konvensional seperti terlalu banyak menggunakan ceramah, kurang menyesuaikan dengan materi pembelajaran, tidak menggunakan media yang menantang dan kegiatan siswa yang kurang memperhatikan lingkungan belajarnya. Pendekatan dengan cara ini diindikasikan berpengaruh terhadap rendahnya motivasi belajar siswa pada saat proses pembelajaran berlangsung.

Kehadiran media pembelajaran interaktif sangat dibutuhkan dalam pembelajaran dikarenakan beberapa faktor yang mempengaruhi belajar seperti faktor jasmaniah, faktor psikologis, faktor sosial. Untuk itu guru harus menggunakan media pembelajaran yang tepat dan interaktif untuk merangsang serta meningkatkan minat belajar dari pada siswa yang selama ini kebiasaan belajar siswa yang hanya memusatkan pada perhatian guru (teacher centered), siswa tidak serius dalam belajar, serta lebih mementingkan pada mata pelajaran kompetensi kejuruan mereka. Juga sekalian mengubah image mata pelajaran Fisika yang sulit, tidak menarik, dan membosankan dikarenakan guru Fisika selama ini hanya berorientasi pada "teacher centered".

Di samping kurangnya penggunaan media pembelajaran interaktif yang tepat, rendahnya perolehan hasil belajar Fisika siswa juga dipengaruhi oleh karakteristik siswa itu sendiri yaitu komunikasi interpersonal (antar pribadi), hal ini dapat dilihat dari kurangnya interaksi siswa pada saat proses pembelajaran berlangsung. Siswa kurang aktif bertanya, hanya menerima apa yang disampaikan oleh guru.

Kehadiran media pembelajaran interaktif dalam proses pembelajaran telah membuat suasana 
yang berbeda dalam kelas, karena materi yang dulunya diajarkan dalam ceramah dan hanya monoton dapat divariasikan dengan menampilkan tayangan berupa integrasi teks, suara, gambar bergerak, dan video.

Melihat hal tersebut di atas, maka perlu dilakukan perbaikan-perbaikan proses pembelajaran secara terus menerus, sehingga siswa lebih termotivasi, lebih aktif, dan juga memiliki komunikasi interpersonal dalam memperlajari mata pelajaran Fisika, sehingga dapat meningkatkan hasil belajar. Salah satu upaya yang dapat dilakukan dengan penggunaan media pembelajaran interaktif, sehingga dapat mendorong siswa lebih mudah dalam memahami konsep-konsep Fisika.

Berdasarkan uraian yang dipaparkan pada latar belakang, identifikasi masalah, dan pembatasan masalah, maka rumusan masalah dalam penelitian ini adalah sebagai berikut :

1. Bagaimana kualitas pengembangan media pembelajaran interaktif yang dikembangkan pada mata pelajaran Fisika?

2. Bagaimana keefektifan pelaksanaan pembelajaran dengan menggunakan media pembelajaran interaktif pada mata pelajaran Fisika dibandingkan dengan pembelajaran konvensional?

\section{METODE}

Analisis data dalam penelitian ini menggunakan analisis deskriptif kuantitatif. Semua data yang terkumpul dianalisis dengan teknik statistik deskriptif yang secara kuantitatif dipisahkan menurut kategori untuk mempertajam penilaian dalam menarik kesimpulan. Data kualitatif yang berupa pernyataan sangat kurang, kurang, sedang, baik, dan sangat baik diubah menjadi data kuantitatif dengan skala nilai 1 sampai 5. Hasilnya diratarata dan digunakan untuk menilai kualitas media pembelajaran.

Alat pengumpul data yang digunakan yaitu test hasil belajar yang berbentuk pilihan berganda yang berjumlah 20 soal yang digunakan untuk mengembangkan keterampilan peserta didik dalam menyelesaikan soal-soal fisika yang di peroleh dari buku pegangan belajar.

Diskriptif statistik diperlukan untuk mencari mean, median, std deviation, variance, range, frekuensi data, grafik data, dan informasi lain yang dibutuhkan. Untuk menentukan nilai ratarata hitung digunakan dengan rumus :

$\bar{X}=\frac{\sum X_{i}}{n}$

(Sudjana, $2005: 67$ )
Untuk menentukan simpangan baku digunakan rumus :

$S=\sqrt{\frac{n \sum X_{i}^{2}-\left(\sum X_{i}\right)^{2}}{n(n-1)}}$

(Sudjana, $2005:$ 94)

Uji ini bertujuan untuk melihat apakah sampel berdistribusi normal atau tidak. Uji yang digunakan dikenal dengan nama Uji Liliefors. Menurut Sudjana (1996: 466), uji normalitas data dilakukan dengan menggunakan uji Liliefors (Lo) dilakukan dengan langkahlangkah berikut. Diawali dengan penentuan taraf sigifikansi, yaitu pada taraf signifikasi 5\% $(0,05)$ dengan hipotesis yang diajukan adalah sebagai berikut :

$\mathrm{H}_{0}$ : Sampel berasal dari populasi yang berdistribusi normal

$\mathrm{H}_{1}$ : Sampel tidak berasal dari populasi yang berdistribusi normal

Dengan kriteria pengujian :

Jika $\mathrm{L}_{\text {hitung }}<\mathrm{L}_{\text {tabel }}$ terima $\mathrm{H}_{0}$, dan

jika $\mathrm{L}_{\text {hitung }}>\mathrm{L}_{\text {tabel }}$ tolak $\mathrm{H}_{0}$

Uji homogenitas data bertujuan untuk mengetahui data mempunyai varians yang homogen atau tidak. Rumus yang digunakan adalah :

$F=\frac{\text { varian terbesar }}{\text { varian terkecil }}$

(Sudjana, 2002:250)

Untuk menguji homogenitas data, digunakan uji kesamaan dua varians. Dalam hal ini pengujian kesamaan varian kedua populasi pada data hasil belajar adalah sebagai berikut:

$$
H_{0}: a_{1}^{2}=a_{2}^{2} \text { dan } H_{a}: a_{1}^{2} \neq a_{2}^{2}
$$

Kriteria pengujian hipotesis :

$$
\begin{aligned}
& \mathrm{H}_{0} \text { diterima jika }: F \leq F_{\left(\frac{1}{2 \alpha}\right)\left(n_{2}-1\right)} \\
& \mathrm{H}_{\mathrm{a}} \text { ditolak jika }: F \geq F_{(1-\alpha)\left(n_{1}-1\right)}
\end{aligned}
$$

Kriteria pengujian hipotesis terima $\mathrm{H}_{0}$ jika $F_{(1-\alpha)\left(n_{1}-1\right)}<F<F_{\left(\frac{1}{2 \alpha}\right)\left(n_{2}-1\right)}$

dimana $F_{\left(\frac{1}{2 \alpha}\right)\left(n_{2}-1\right)}$ diperoleh dari daftar distribusi $\mathrm{F}$ dengan $\mathrm{dk}$ pembilang $=\mathrm{n}$ dan $\mathrm{dk}$ penyebut $=\mathrm{n}$ pada taraf nyata $\alpha=5 \%$.

Dimana:

$\mathrm{n}_{1}=$ nilai kelas yang diberi pembelajaran media pembelajaran interaktif (kelas eksperimen)

$\mathrm{n}_{2}=$ nilai kelas yang diberi pembelajaran menggunakan media konvensional (kelas kontrol) 


\section{Pengujian Hipotesis}

Setelah kedua data penelitian telah memenuhi kriteria berdistribusi normal dan homogen, selanjutnya dilakukan pengujian hipotesis dengan uji-t.

Hipotesis yang diuji berbentuk:

$\begin{aligned} \mathrm{H}_{\mathrm{o}}: \mu_{1}=\mu_{2}: & \text { tidak ada perbedaan hasil } \\ & \text { belajar siswa yang } \\ & \text { menggunakan media interaktif } \\ & \text { dengan hasil belajar siswa } \\ & \text { yang menggunakan media } \\ & \text { konvensional } \\ \mathrm{H}_{\mathrm{o}}: \mu_{1} \neq \mu_{2}: & \text { ada perbedaan hasil belajar } \\ & \text { siswa yang menggunakan } \\ & \text { media interaktif dengan hasil } \\ & \text { belajar siswa yang } \\ & \text { menggunakan } \\ & \text { konvensional media }\end{aligned}$

Untuk melakukan uji-t independen, menggunakan rumus adalah sebagai berikut :

$t_{\text {hit }}=\frac{\bar{X}_{1}-\bar{X}_{2}}{\sqrt[s]{\frac{1}{n_{1}}-\frac{1}{n_{2}}}}$

(Sudjana, 2002:249)

dengan $\mathrm{S}$ adalah varians gabungan yang dihutung dengan rumus :

$S^{2}=\frac{\left(n_{1}-1\right) S_{1}^{2}+\left(n_{2}-1\right) S_{2}^{2}}{\left(n_{1}+n_{2}\right)-2}$

(Sudjana, 2002:239)

Selanjutnya kriteria pengujian hipotesis adalah terima Ha jika $t_{\text {hitung }}>t_{\text {tabel }}$ yang di dapat dari tabel independent sample test dengan $\mathrm{dk}=(\mathrm{n}-$ 1) dan taraf $\alpha=5 \%$.

\section{Uji Efektifitas}

Untuk melihat keefektifan media pembelajaran interaktif yang dieksperimenkan,digunakan analisis deskriptif kuantitatif.

Menurut Sugiyono (2010) dalam perhitungan efektivitas digunakan skala Likert, di mana semakin besar skor yang diperoleh maka tingkat efektivitas dikatakan semakin tinggi/baik, demikian sebaliknya semakin kecil perolehan skor yang diperoleh maka tingkat keberhasilan penggunaan media pembelajaran interaktif semakin sedikit.

Semua data yang terkumpul dianalisis dengan teknik statistik deskriptif yang secara kuantitatif dipisahkan menurut kategori untuk mempertajam penilaian dalam menarik kesimpulan. Data kualitatif berupa pernyataan sangat kurang efektif, kurang efektif, tidak efektif, efektif, dan sangat efektif, diubah menjadi data kuantitatif dengan skala 1 sampai 5. Hasilnya dirata-rata dan digunakan untuk menilai efektivitas pembelajaran. Kriteria efektif akan dikonversikan menjadi nilai dengan skala lima menggunakan skala Likert yang di analisis secara deskriptif persentase dengan menggunakan rumus perhitungan efektivitas berikut:

$$
\begin{aligned}
& \text { Efektifitas }= \\
& \text { jumlah skor yang diperoleh } \\
& \text { jumlah skor ideal seluruh item }
\end{aligned} 100 \%
$$

(Sugiyono : 2010)

Adapun kriteria penilaian efektivitas dalam penelitian ini dengan mengacu pada skala dan klasifikasi dari Tabel 3.7. berikut ini :

Tabel 3.7. Kriteria Penelitian Efektifitas Multimedia

\begin{tabular}{|c|l|l|}
\hline Nilai & \multicolumn{1}{|c|}{ Kriteria } & \multicolumn{1}{c|}{ Persentase } \\
\hline A & Sangat Efektif & $81 \%-100 \%$ \\
\hline B & Efektif & $61 \%-80 \%$ \\
\hline C & Tidak Efektif & $41 \%-60 \%$ \\
\hline D & Kurang Efektif & $21 \%-40 \%$ \\
\hline E & $\begin{array}{l}\text { Sangat Kurang } \\
\text { Efektif }\end{array}$ & $0 \%-20 \%$ \\
\hline \multicolumn{3}{|c|}{ X = skor empiris } \\
\end{tabular}

Dari Tabel 3.7. tersebut menunjukkan bahwa jika perolehan apabila persentase mencapai 81 persen sampai 100 persen berarti sangat efektif, pencapaian 61 persen sampai 80 persen efektif, dikatakan tidak efektif jika persentase pencapaian 41 persen hingga 60 persen, kategori kurang efektif jika pencapaian di antara 21 persen hingga 40 persen, dan sangat kurang efektif adalah pencapaian di antara 0 hingga 20 persen.

\section{HASIL DAN PEMBAHASAN \\ Hasil}

Dari hasil penelusuran angket yang telah disebarkan bahwa $100 \%$ dari siswa menyatakan membutuhkan media pembelajaran pada kompetensi momentum \& impuls pada mata pelajaran Fisika, agar dapat mereka jadikan sebagai salah satu sarana pembelajaran secara individual serta memahami penerapan impuls \& momentum dalam kehidupan seharihari dan $83,3 \%$ dari guru-guru menyatakan membutuhkan media pembelajaran interaktif pada pelajaran Fisika agar proses pembelajaran berjalan lebih efektif dan menarik. Hasil wawancara lisan kepada guru mata pelajaran 
Fisika, menyatakan bahwa pembelajaran Fisika membutuhkan multimedia interaktif untuk menunjang proses pembelajaran saat dalam ruang kelas maupun di luar ruangan kelas karena sulitnya mendapatkan media pembelajaran yang efektif untuk menyampaikan materi Fisika secara langsung.

Berdasarkan validasi produk melalui serangkaian uji coba dan revisi yang telah dilakukan, maka multimedia pembelajaran berbasis interaktif pada mata pelajaran Fisika dengan materi momentum dan impuls telah memiliki status valid. Uji coba dilakukan 4 tahap, yaitu: (1) evaluasi ahli materi, ahli desain pembelajaran, dan ahli rekayasa perangkat lunak, (2) uji coba perorangan, (3) uji coba kelompok kecil, dan uji coba lapangan.

Hasil penilaian oleh ahli materi, ahli desain pembelajaran, dan ahli rekayasa perangkat lunak pada setiap aspek penilaian secara keseluruhan ditentukan oleh skor ratarata pada kategorinya masing-masing. Hasil penilaian tersebut kemudian dianalisis untuk menentukan layak tidaknya dikembangkan media pembelajaran interaktif pada pembelajaran Fisika.

Uji normalitas dibuat untuk mencari kenormalan dari sampel yang diteliti. Uji normalitas menggunakan rumus Uji Liliefors (Sudjana, 2005: 466). Setelah dilakukan perhitungan, untuk kelas yang menggunakan media pembelajaran interaktif di peroleh nilai $\mathrm{L}_{\text {hitung }}=0,1384$ sedangkan $\mathrm{L}_{\text {tabel }}$ pada taraf $\alpha=$ 0,05 dan $\mathrm{n}=32$ adalah 0,1566. Hal ini menunjukkan $\mathrm{L}_{\text {hitung }}<\mathrm{L}_{\text {tabel }}$ artinya sampel berasal dari populasi yang berdistribusi normal.

Sedangkan uji normalitas nilai pretes untuk kelas konvensional di peroleh nilai $\mathrm{L}_{\text {hitung }}$ $=0,1403$ sedangkan $\mathrm{L}_{\text {tabel }}$ pada taraf $\alpha=0,05$ dan $\mathrm{n}=32$ adalah 0,1566 . Hal ini menunjukkan $\mathrm{L}_{\text {hitung }}<\mathrm{L}_{\text {tabel }}$ artinya sampel berasal dari populasi yang berdistribusi normal.

Rangkuman persentase rata-rata hasil penilaian terhadap media pembelajaran interaktif pada pembelajaran Fisika oleh ahli materi, ahli desain pembelajaran, ahli rekayasa perangkat lunak, uji coba perorangan, uji coba kelompok kecil, dan uji coba lapangan dapat di lihat pada tabel 2 berikut:

Tabel 2. Rangkuman Persentase Rata-Rata Hasil Penilaian Terhadap Media Pembelajaran Interaktif pada Pembelajaran Fisika

\begin{tabular}{|c|l|c|c|}
\hline No. & \multicolumn{1}{|c|}{ Kategorisasi } & \% Rerata & Kriteria \\
\hline 1 & Ahli materi & $86,22 \%$ & Sangat Baik \\
\hline 2 & Ahli desain pembelajaran & $84,29 \%$ & Sangat Baik \\
\hline 3 & Ahli rekayasa perangkat lunak & $91,34 \%$ & Sangat Baik \\
\hline 4 & Siswa pada uji coba perorangan & $90,72 \%$ & Sangat Baik \\
\hline 5 & Siswa pada uji coba kelompok kecil & $95,50 \%$ & Sangat Baik \\
\hline 6 & Siswa pada uji coba lapangan & $97,95 \%$ & Sangat Baik \\
\hline \multicolumn{2}{|c|}{ RATA - RATA } & $\mathbf{9 1 , 0 0 \%}$ & Sangat Baik \\
\hline
\end{tabular}

Hasil pengolahan data penelitian yang telah dilakukan, rata-rata hasil penilaian pada tabel 4.48 menunjukkan bahwa media pembelajaran interaktif yang digunakan termasuk kategori "Sangat Baik" sehingga dapat disimpulkan bahwa penggunaan media pembelajaran interaktif layak untuk digunakan pada pembelajaran Fisika pada standar kompetensi Momentum dan Impuls.

\section{Pembahasan}

Dari hasil pengolahan data penelitian yang dilakukan, terdapat perbedaan hasil belajar Fisika antara siswa yang dibelajarkan dengan menggunakan media pembelajaran interaktif dengan peserta didik yang dibelajarkan dengan pembelajaran konvensional, yaitu nilai rata-rata hasil belajar Fisika yang dibelajarkan dengan media pembelajaran interaktif lebih tinggi dibandingkan dengan nilai rata-rata hasil belajar peserta didik yang dibelajarkan dengan pembelajaran konvensional. Hal itu dapat dilihat dari nilai rata-rata hasil belajar Fisika peserta didik yang dibelajarkan dengan menggunakan media pembelajaran interaktif yaitu sebesar 18,94 (59,18\%), sedangkan nilai rata-rata hasil belajar Fisika peserta didik yang dibelajarkan dengan pembelajaran konvensional yaitu sebesar 16,94 (54,65\%). Dari data ini membuktikan bahwa penggunaan media pembelajaran interaktif lebih baik dalam meningkatkan pengetahuan peserta didik dalam pembelajaran interaktif Fisika dari pada pembelajaran konvensional.

Penggunaan media interaktif dalam pembelajaran momentum \& impuls siswa dapat 
berinteraksi langsung dan melakukan kontrol langsung pada sumber informasi, sehingga siswa dapat mengendalikan dan memperoleh apa yang dibutuhkan, misalnya mempelajari tentang tumbukan lenting sempurna dan tumbukan tak lenting sama sekali dalam aplikasinya di kehidupan sehari-hari. Siswa juga dapat berlatih nejawab soal/latihan yang telah dilengkapi dengan umpan balik sehingga siswa dapat mengetahui kesalahan yang telah dilakukan dalam mengerjakan latihan. Media pembelajaran interaktif juga dilengkapi dengan rangkuman sehingga ssiwa dapat memperoleh ringkasan materi yang disampaikan.

Pembelajaran dengan media interaktif juga membantu guru untuk mudah mengontrol sejauh mana materi yang sedang dipelajari siswa yang sesuai dengan karakter dan kemampuan yang berbeda-beda, sedangkan pembelajaran konvensional siswa tidak berinteaksi langsung pada sumber informasi yang didominasi oleh guru yang disampaikan secara klasikal. Walaupun dalam penelitian ini di peroleh data bahwa hasil belajar Fisika peserta didik lebih tinggi jika dibelajarkan dengan media pembelajaran interaktif daripada hasil pembelajaran Fisika peserta didik yang dibelajarkan dengan pembelajaran konvensional, namun dalam pelaksanaannya kedua media pembelajaran ini telah mampu meningkatkan pemahaman dan hasil belajar Fisika peserta didik. Keefektifan penggunaan media pembelajaran interaktif adalah sebesar $75,75 \%$ dan pembelajaran konvensional sebesar $67,74 \%$.

$$
\text { Dapat disimpulkan bahwa }
$$

pembelajaran dengan menggunakan media interaktif dapat meningkatkan kompetensi dan pengetahuan siswa yang berarti media interaktif telah teruji.

\section{PENUTUP Simpulan}

Dengan melaksanakan tahapan-tahapan penelitian pengembangan Borg \& Gall, mulai dari penelitian pendahuluan, membuat desain, pemilihan bahan pelajaran, perekaman, audio, dan produksi media. Media pembelajaran interaktif yang dihasilkan harus melewati beberapa tahapan mulai dari (a) validasi oleh ahli materi, (b) validasi oleh ahli desain pembelajaran, (c) validasi oleh ahli rekayasa perangkat lunak, (d) uji coba perorangan, (e) uji coba kelompok kecil, sampai dengan (f) uji lapangan kepada peserta didik, produk media pembelajaran interaktif untuk pembelajaran Fisika memiliki hasil sudah layak menjadi produk akhir yang dapat disebarluaskan dan diimplementasikan kepada para pengguna.

Untuk melihat efektifitas produk, dilakukan analisis terhadap hasil belajar peserta didik. Berdasarkan analisis dari 32 peserta didik uji coba kelompok besar hasil penggunaan media pembelajaran interaktif pada pembelajaran Fisika pada tes hasil belajar peserta didik menunjukkan bahwa hasil belajar peserta didik yang dibelajarkan dengan menggunakan media pembelajaran interaktif Fisika nilai rata-rata sebesar 18,94 (59,18\%), sedangkan nilai rata-rata hasil belajar Fisika peserta didik yang dibelajarkan dengan pembelajaran konvensional yaitu sebesar 16,94 (54,65\%). Dari data ini membuktikan bahwa penggunaan media pembelajaran interaktif lebih baik dalam meningkatkan pengetahuan peserta didik dalam pembelajaran interaktif Fisika dari pada pembelajaran konvensional.

Berdasarkan data hasil efektifitas produk bahwa hasil belajar peserta didik yang diajarkan dengan menggunakan media pembelajaran interaktif Fisika lebih efektif dari pada dengan hasil belajar peserta didik yang diajarkan dengan pembelajaran konvensional, diketahui juga data hasil media pembelajaran interaktif Fisika memiliki keefektifan sebesar $75,75 \%$ lebih tinggi dari keefektifan pembelajaran konvensional sebesar 67,74\%.

Produk media pembelajaran interaktif layak digunakan, mudah dipelajari sehingga menjadi salah satu bagian kegiatan pembelajaran untuk mata pelajaran Fisika dengan standar kompetensi Momentum dan Impuls.

\section{Saran}

Penggunaan media pembelajaran perlu diadakan pengontrolan terhadap guru yang menggunakan media pembelajaran. Guru harus memiliki profesionalitas yang sama, latar belakang pendidikan yang sama, serta penampilan yang hampir sama dalam menggunakan media pembelajaran. Jika digunakan media pembelajaran yang baru perlu adanya pelatihan terhadap guru atas penggunaan media pembelajaran sehingga mempermudah guru dalam penyampaian tahapan-tahapan dalam pembelajaran.

Mengingat selama ini proses pembelajaran masih menggunakan media cetak, maka disarankan agar dapat menambahkan media pembelajaran ini sebagai salah satu media pembelajaran yang digunakan untuk proses pembelajaran, sehingga kegiatan 
pembelajaran lebih bervariasi, menarik, dan tidak membosankan.

Perlu diadakannya kesiapan fasilitas pendukung dalam menggunakan media pembelajaran interaktif, misalnya komputer, infokus proyektor. Dalam hal kelengkapan fasilitas seperti komputer dan infokus proyektor tidak semua sekolah pasti memilikinya sehingga perlu digunakan media pembelajaran yang sesuai dengan kebutuhan sekolah.

Kepada peneliti selanjutnya, diharapkan pembelajaran dengan menggunakan media pembelajaran interaktif mengharuskan guru menyesuaikan isi materi dan penggunaan waktu jam pelajaran, sehingga dapat mempengaruhi hasil belajar siswa, khususnya pada hasil belajar Fisika.

Kepada guru agar kiranya memberikan motivasi kepada peserta didik untuk dspat belajar dengan menggunakan media pembelajaran interaktif, karena peserta didik akan mendapat informasi yang mereka inginkan sesuai kemampuan masing-masing melalui media pembelajaran ini dan peserta didik juga tidak tergantung terhadap kehadiran guru dalam upaya meningkatkan hasil belajarnya.

\section{DAFTAR PUSTAKA}

Arief S Sadiman, dkk. (2003). Media pendidikan, pengertian, pengembangan, dan pemanfaatannya. Jakarta : CV. Rajawali Pers

Arsyad, Azhar. (2013). Media Pembelajaran. Jakarta: Rajawali Press.

Budiningsih, C. Asri. (2005). Belajar dan Pembelajaran. Jakarta: Rineka Cipta

Borg, W \& V Gall, M.D. (2005). Applying Educational Research ( $5^{\text {th }}$ ed), USA

Dick, W, dan Carey, L. (2005). The systematic design of instruction. United States of America: Scoot Foresman and Company

Ena,O.T.(2001). Membuat media pembelajaran multimedia interaktif dengan piranti lunak presentasi. Jurnal. Yogyakarta: Indonesian Language and Culture Intensive Course

Fraenkel \& Wallen. (1990). How to Design and Evaluate Research in Education. New York: McGraw-Hill, Inc

Gagne, R.M. (1985). The Conditioning of Learning. Third Edition. New York: Hot, Rinehart and Winston

Gilkey, Richard dkk. (1976). Satuan Tugas Defenisi dan Terminology AECT. Jakarta: Rajawali
Hamalik, O. (2005). Perencanaan pengajaran berdasarkan pendekatan sistem. Jakarta: Bumi Aksara

Hamid, A.K. (1992). Teori belajar dan pengajaran. Medan: Pasca Sarjana Unimed

ITB. (2008). Modul pelatihan multimedia. Bandung: Puskom ITB

John D. Latuheru. (1988). Media pembelajaran dalam proses belajar mengajar masa kini. Jakarta : Depdikbud

Kemble, E.C. (1966). Physical science, its structure and development. Messachusetts : The M.I.T. Press

Pidarta, Made. (2009). Landasarn Kependidikan. Jakarta: Rineka Cipta

Sudjana, N \& Rivai, A. (2003). Teknologi pengajaran. Bandung : Sinar Baru Algensindo

Sadiman, A., dkk. (2003). Media Pendidikan: Pengertian, Pengembangan, dan Pemanfaatannya. Jakarta. Seri Pustaka Teknologi Pendidikan No. 6. Rajawali

Schocolnik, Miriam. (1999). Using Presentation Software to Enhance Language Learning. The Internet TESL Journal, Vol. V, No.3, March 1999, http:/www.aitech.ac.jp/ iteslj/

Smaldino, E.S. dkk. (2008). Instructional Technology and Media for Learning. New Jersey : Upper Saddle River.

Sudjana.(2002).Metoda Statistika. Bandung : Tarsito

Sudjana, Nana. (2004). Penilaian Hasil Proses Belajar Mengajar. Bandung : Rosdakarya

Sugiyono. (2003). Metode Penelitian Administrasi. Bandung : CV. Alfabeta

(2010). Metode Penelitian Kuantitatif, Kualitatif, dan $R \& D$. Bandung : C.V. Alfabeta

Yusufhadi Miarso. (1994). Defenisi teknologi pendidikan : Satuan tugas defenisi dan terminology AECT. Washinton, D.C : AECT (buku asli diterbitkan tahun 1977)

Winkel, W.S. (1984).Psikologi Pengajaran. Jakarta : Gramedia 